Article

\title{
Application of CCG Sensors to a High-Temperature Structure Subjected to Thermo-Mechanical Load
}

\author{
Weihua Xie ${ }^{1}$, Songhe Meng ${ }^{1, *}$, Hua Jin ${ }^{1, *}$, Chong Du ${ }^{2}$, Libin Wang ${ }^{1}$, Tao Peng ${ }^{1}$, \\ Fabrizio Scarpa ${ }^{3}$ and Chenghai $\mathrm{Xu}^{1}$ \\ 1 Centre for Composite Materials and Structures, Harbin Institute of Technology, Harbin 150080, China; \\ michael@hit.edu.cn (W.X.); wanglibin_hit@163.com (L.W.); boypengtao@163.com (T.P.); \\ hit-xuchenghai@163.com (C.X.) \\ 2 Shanghai Advanced Research Institute, Chinese Academy of Sciences, Shanghai 201210, China; \\ duc@sari.ac.cn \\ 3 Advanced Composites Centre for Innovation and Science (ACCIS), University of Bristol, \\ Bristol BS8 1TR, UK; f.scarpa@bristol.ac.uk \\ * Correspondence: mengsh@hit.edu.cn (S.M.); jinhua2007@hit.edu.cn (H.J.); \\ Tel.: +86-451-8641-7560 (S.M.); Tel.: +86-451-8640-2343 (H.J.)
}

Academic Editors: Teen-Hang Meen, Shoou-Jinn Chang, Stephen D. Prior and Artde Donald Kin-Tak Lam Received: 31 July 2016; Accepted: 19 September 2016; Published: 13 October 2016

\begin{abstract}
This paper presents a simple methodology to perform a high temperature coupled thermo-mechanical test using ultra-high temperature ceramic material specimens (UHTCs), which are equipped with chemical composition gratings sensors (CCGs). The methodology also considers the presence of coupled loading within the response provided by the CCG sensors. The theoretical strain of the UHTCs specimens calculated with this technique shows a maximum relative error of $2.15 \%$ between the analytical and experimental data. To further verify the validity of the results from the tests, a Finite Element (FE) model has been developed to simulate the temperature, stress and strain fields within the UHTC structure equipped with the CCG. The results show that the compressive stress exceeds the material strength at the bonding area, and this originates a failure by fracture of the supporting structure in the hot environment. The results related to the strain fields show that the relative error with the experimental data decrease with an increase of temperature. The relative error is less than $15 \%$ when the temperature is higher than $200{ }^{\circ} \mathrm{C}$, and only $6.71 \%$ at $695{ }^{\circ} \mathrm{C}$.
\end{abstract}

Keywords: fibre optic sensors; strain and temperature; chemical composition gratings (CCGs); high temperature application; hot structure; thermo-mechanical

\section{Introduction}

Over the past two decades many fibre Bragg grating (FBG)-based sensors have been developed for applications in high-temperature environments due to their unique features [1-4]. Some examples of the interesting characteristics that characterise FBGs are their low weight, compact size, electromagnetic and radiofrequency compliance, durability, long-distance transmission capabilities and good heat resistance [5,6]. FBG sensors are regrouped into classes that include type I, type II and long-period gratings, photonic crystal fibres, sapphire gratings and chemical composition gratings (CCGs), the latter also commonly called regenerated FBGs (RFBGs). RFBGs have been used in environments up to $1295{ }^{\circ} \mathrm{C}$ [7] and are typically produced from hydrogen-loaded optical fibres by applying an annealing treatment at temperatures between $800^{\circ} \mathrm{C}$ and $1000^{\circ} \mathrm{C}$ [8]. The original grating is completely erased and a new grating refractive index modulation is generated following the annealing process. The main advantages of RFBGs are their ultrahigh temperature stability, good grating qualities and their potential for measuring reflected light. 
To produce stable thermal sensors for high temperature environments Fokine [9-14], Zhang [15,16], Canning [7,17-19], Barrera [20-22], Guan [23-25] and others [26-30] have devoted significant efforts to the study of the design, production and related technologies of RFBGs. Recently, a number of research groups have also begun to focus their efforts on the application of RFBGs in high-temperature environments. Issues related the utilisation of RFBGs in these challenging environmental conditions are related to the safe packaging and installation of the sensors in structures, because silica-based RFBGs are extremely brittle and fragile after the annealing process [1]. Méndez et al. [31,32], Selfridge et al. [33], Sai Prasad and co-workers [34] have used metal substrates to provide the connection between the optical fibre sensors and the structure. Mamidi et al. [35], Reddy et al. [36], Barrera et al. [37,38] and Azhari et al. [39] have also used a metal or ceramic tube to encapsulate the RFBGs to perform measurements in high temperature environments.

In a previous work [40] we have described a simple method to apply CCG sensors on ultra-high temperature ceramic materials (UHTCs) in order to measure strains in thermal environments up to $1000{ }^{\circ} \mathrm{C}$. This background work has shown the promise of using CCGs for applications in high temperature environments. Aerospace hot structures and thermal protection systems (TPS) are examples of some of the most likely applications for CCG sensors, which are subjected to simultaneous thermal and mechanical load [41]. The thermo-mechanical coupling makes the measurement of high temperature strains however extremely difficult and expensive. In this paper we present an experimental method that can identify the presence of a simultaneous thermal and mechanical load on a structure subjected to high temperatures by using CCGs. We carry out a thermo-mechanical experiment related to the application of CCGs on an ultra-high temperature ceramic material (UHTC) structure. The results from the experiments and from theoretical formulas are compared and analysed. We also develop a FE model to simulate the experiments and explain the failure mechanism based on the stress distribution and strain field variation. The relative errors between the CCG sensor and FE method related to the strain measurements are also compared and discussed.

\section{Experimental Design}

The experimental setup used in this work (Figure 1) was designed to simulate a realistic service condition represented by a thermal protection shield (TPS) on a hot external structure, like in hypersonic vehicles [42,43]. The UHTC specimen [40] was heated vertically from the bottom through the hole on the workbench. The diameter of the heating spot was $20 \mathrm{~mm}$ and the distance from the laser heating-lens mounted at the bottom of the gantry to the specimen was $200 \mathrm{~mm}$. The vertical displacement of the UHTC specimen was fixed by a horizontal vice along the two borders. The minimum force was adjusted to produce a friction force to balance the weight of the specimen.

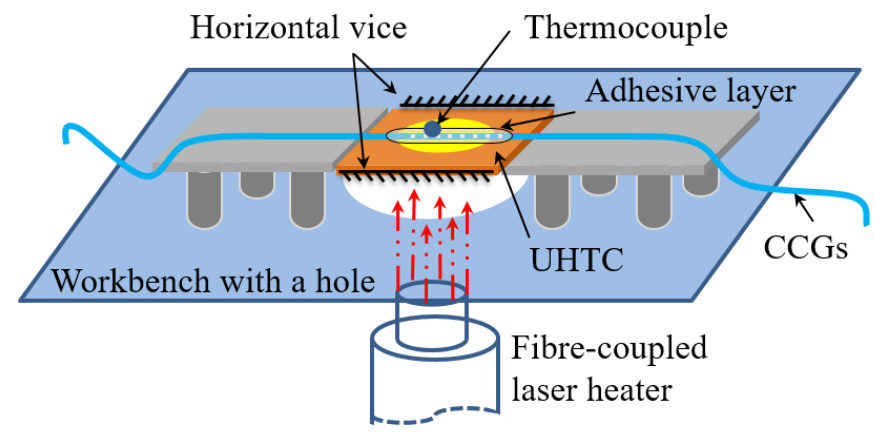

Figure 1. Scheme illustrating thermal-mechanical experimental apparatus.

Corundum ceramic plates were placed on the contact area between the UHTC specimen and the horizontal vice to reduce heat transfer. In this situation, the thermal expansion of the UHTC in a vertical direction was restricted upon heating and a compression stress was then induced along this 
direction. The CCG sensor was attached to the surface of the UHTC along the horizontal direction to measure its thermo-mechanical response.

The CCG sensor used in this study was fabricated using Ge-doped silica fibres at the Institute of Photonics Technology (Jinan University, Guangzhou, China). A high-purity alumina adhesive (Rebond 989FS, Cotronics Corp., New York, NY, USA) was used to connect the CCG to the specimen. The size of the specimen was $40 \mathrm{~mm} \times 45 \mathrm{~mm} \times 5 \mathrm{~mm}$. The UHTC sample used in this study was fabricated from commercial $\mathrm{ZrB}_{2}$ (Northwest Institute for Non-ferrous Metal Research, Xi'an, China) and SiC powders (Weifang Kaihua Micro-powder Co. Ltd., Weifang, China). The powder mixtures of $\mathrm{ZrB}_{2}$ with $15 \% \mathrm{v} / \mathrm{v} \mathrm{SiC}$ were ball-milled in ethanol for eight hours with a hard milling tool and dried in a rotating evaporator. Milled powder was then hot-pressed uniaxially in a boron nitride coated graphite die at $1950^{\circ} \mathrm{C}$ for $60 \mathrm{~min}$ under a vacuum and $30 \mathrm{MPa}$ of pressure was applied, giving it good oxidative stability up to $2000^{\circ} \mathrm{C}$ [44].

A high-power fibre-coupled laser (DILAS Diodenlaser $\mathrm{GmbH}$, Mainz-Hechtsheim, Germany. Laser class: Compact-980.10-1500C, output power: $1500 \mathrm{~W}$, wavelength: $980 \mathrm{~nm} \pm 10 \mathrm{~nm} @ 25^{\circ} \mathrm{C}$ ) was used to heat the specimen in this study. The temperature of the specimen was controlled by adjusting the laser heater output power according to the temperature response data. An optical fibre-grating demodulator (si425 Optical Sensing Interrogator, Micron Optics, Inc., Atlanta, GA, USA) was used to record reflected wavelength signals. A thermocouple was mounted on the adhesive layer to measure the temperature of the specimen and a multi-channel temperature signal acquisition instrument (LR8402-21, HIOKI, Nagano, Japan) was used to record temperature responses. The thermocouple signal was mainly used for temperature compensation, which is generally adopted to decouple CCGs signals [45].

\section{Experimental Results and Analysis}

\subsection{Experimental Results}

The designed experimental rig is shown in Figure 2. The thermo-mechanical experimental test was performed using a CCG sensor with centre wavelengths of $1550.521 \mathrm{~nm}$. During the test, the specimen was slowly heated by adjusting the output power of the laser heater, and the response of the CCG sensor and thermocouples was recorded by the instruments. The test stopped when the UHTC specimen fractured at $695^{\circ} \mathrm{C}$.

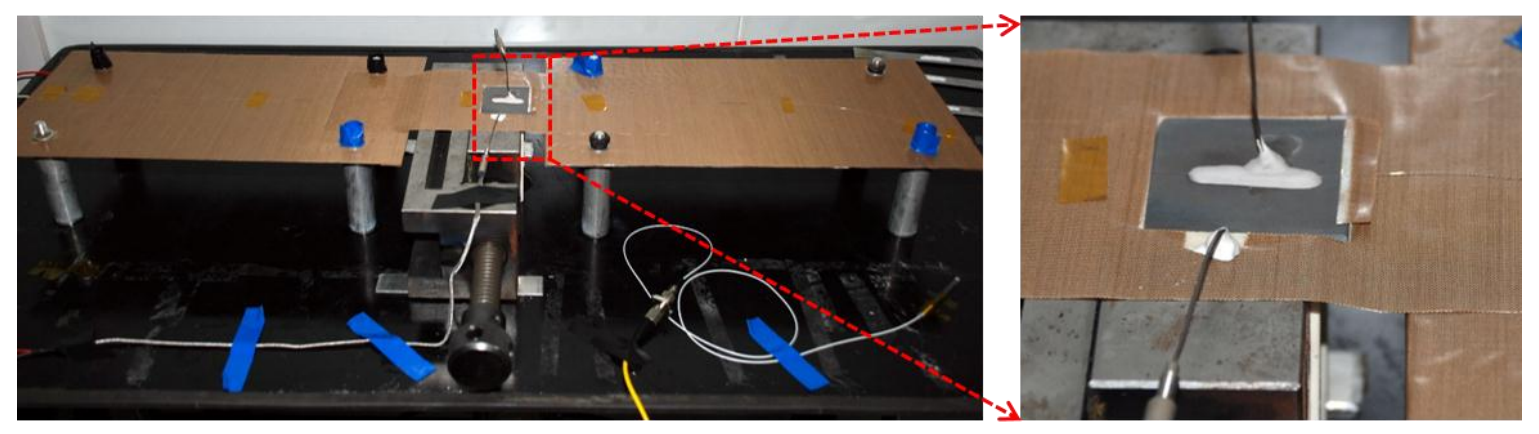

Figure 2. Experimental rig for the thermo-mechanical test.

The fracture was located at the centre of the specimen in an area parallel to the direction of the CCG sensor (Figure 3). During the test the specimen's compression stress along the vertical direction increased alongside the temperature, because its expansion at that direction was constrained by the horizontal vice. Cracks were generated when local stress exceeded the UHTCs strength at that specific temperature, and the fracture occurred with propagating cracks due to the fragility of the UHTCs. 


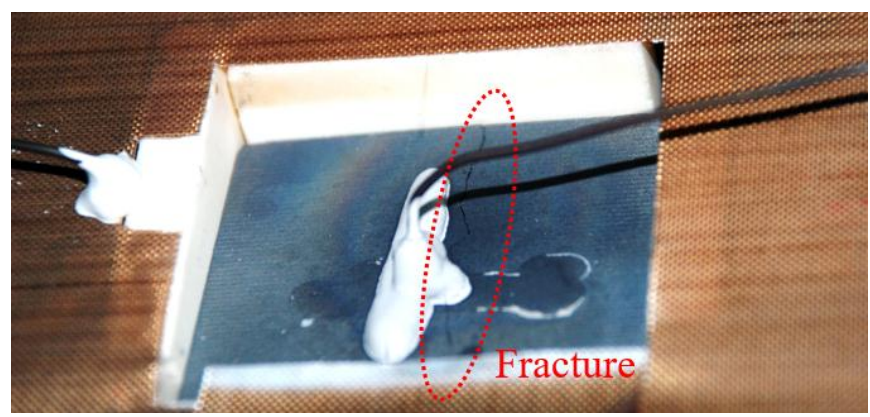

Figure 3. Photo of UHTC specimen with a fracture after a test.

The curve of the measured response signals from the CCGs versus the temperature is shown in Figure 4a. As can clearly be observed from that plot, the response of the wavelength presents a nonlinear increase versus the temperature. Nonlinearity is affected by many factors, such as the highly temperature-dependent nature of the thermo-optical coefficient and the thermal expansion coefficient of the silica fibres [46], the variation in the period of the optical fibre sensor and the elastic-optic coefficient [47]. Figure $4 \mathrm{~b}$ shows the results of the relative variation in wavelength versus temperature, as well as the quadratic curve-fitting of the experimental data. Table 1 lists the curve fitting parameters with a $95 \%$ confidence interval. Similar quadratic thermal responses have been recorded in other studies [40,48-50].

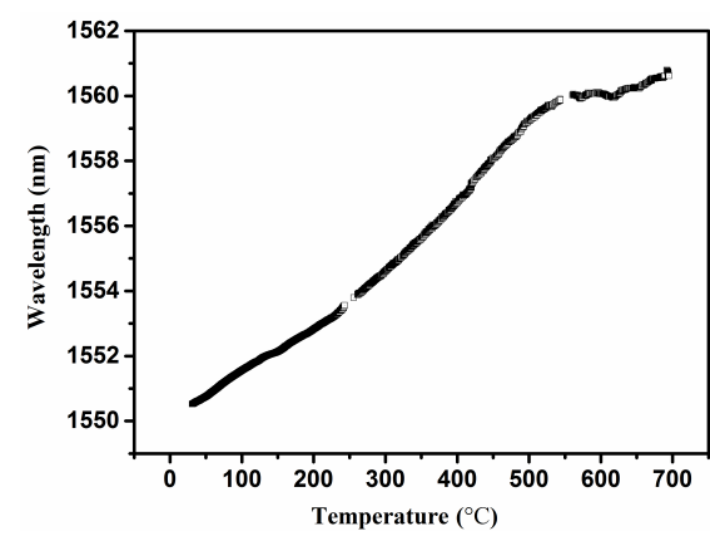

(a)

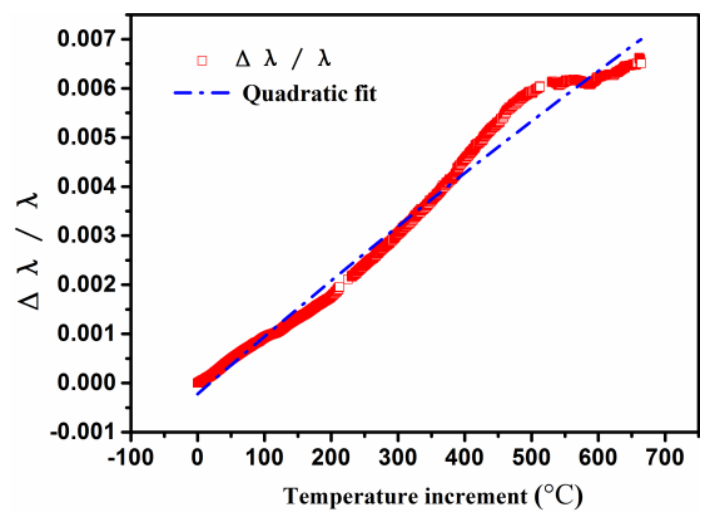

(b)

Figure 4. (a) Variation and (b) relative variation of wavelength alongside temperature.

Table 1. Fitting parameters of experimental data $\left(R^{2}=0.986\right)$.

\begin{tabular}{ccc}
\hline Parameter & Value & Standard Error \\
\hline Coefficient of the first-order term $K_{T 1}$ & $1.18 \times 10^{-5}$ & $9.98 \times 10^{-8}$ \\
Coefficient of the second-order term $K_{T 2}$ & $-1.39 \times 10^{-9}$ & $1.52 \times 10^{-10}$ \\
Universal constant C & $-2.20 \times 10^{-4}$ & $1.28 \times 10^{-5}$ \\
\hline
\end{tabular}

\subsection{Analysis of the Results}

We have used Equation (1) [50] to denote the quadratic relationship between the relative variation of the measured total wavelength response $\Delta \lambda_{B} / \lambda_{B}$ and the temperature:

$$
\frac{\Delta \lambda_{B}}{\lambda_{B}}=K_{T 1} \Delta T+K_{T 2} \Delta T^{2}+C
$$


where $K_{T 1}$ represents the coefficient of the first-order term, $K_{T 2}$ represents the coefficient of the second-order term, and $C$ is a universal constant. The first-order term coefficient $K_{T 1}$ can also be written in the following form [40]:

$$
K_{T 1}=(\alpha+\zeta)+K_{\varepsilon} \beta\left(\alpha_{s}-\alpha\right)
$$

where $\alpha, \zeta$ and $K_{\varepsilon}$ denote the thermal expansion coefficient, thermo-optical coefficient and strain sensitivity coefficient of the CCGs, respectively. The term $\alpha_{s}$ denotes the thermal expansion coefficient of the UHTC and $\beta$ is the strain transfer coefficient used to characterise the strain difference between the structural and the actual sensed strains induced by the adhesive layer. The sensed strain can be represented by the actual structural strain multiplied by factor $\beta$ [50]:

$$
\varepsilon_{C}=\beta\left(\alpha_{S}-\alpha\right) \Delta T
$$

where $\varepsilon_{C}$ denotes the CCGs-sensed strain along the horizontal direction for this test.

From Equations (2) and (3) it is possible to derive the following relation:

$$
\varepsilon_{C}=\frac{K_{T 1}-(\alpha+\zeta)}{K_{\varepsilon}} \Delta T
$$

The strain values $\varepsilon_{C}$ sensed by CCGs can be calculated using Equation (4) from the experimental data. Then, the practical structural strain can be calculated by the following equation, while the values of $\beta$ at different temperatures can be found from [40]:

$$
\varepsilon_{S}=\varepsilon_{C} / \beta
$$

The theoretical strain of the specimen can be solved by considering the thermal deformation relations. If we denote $\varepsilon_{T h}$ as the theoretical strain of the specimen along the horizontal direction (CCGs' direction), its final value contains the effects of the strain in both horizontal and vertical directions:

$$
\varepsilon_{T h}=\left(\alpha_{s}-\alpha\right) \Delta T+v\left(\alpha_{s}-\alpha\right) \Delta T
$$

where $v$ is the Poisson's ratio of the UHTC material. Figure 5 shows a comparison between the experimental and theoretical strain. One can observe the existence of good agreement between the two data sets. The nonlinear experimental strain in Figure 5 was calculated by using Equation (4), in which the parameter $K_{T 1}$ has been obtained from the response signals of the CCGs. The theoretical strain in Figure 5 was calculated by using Equation (5). The maximum relative error is $2.15 \%$, indicating that the CCGs sensor can provide a good strain measurement under thermo-mechanical loading for the external hot structure to which it is applied.

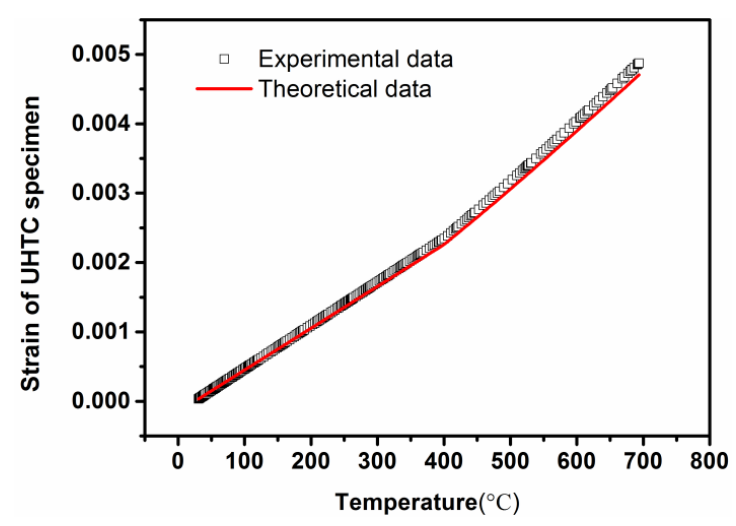

Figure 5. Comparison of theoretical and experimental strains. 


\section{Finite Element Analysis and Discussions}

\subsection{Finite Element Model}

A finite element method (FEM) was used to simulate the thermo-mechanical test process. It is worth mentioning that the use of a robust FE model to represent the phenomenon could be instrumental to reduce the time available for the experimental tests, and especially the financial costs associated to full-scale experimental trials. A full-size three-dimensional model of the UHTC specimen and the adhesive layer was built using the finite element analysis (FEA) software (ANSYS, Version 16.1), as shown in Figure 6a. The FE model was assumed to be a combination of two quarter-spheres and a half-cylinder, approximately. The detailed dimensions of the adhesive layer and UHTC specimen used in this study are shown in Table 2. The CCG sensor was ignored in the FE model due to its small size. The material properties of the UHTC and adhesive are shown in Tables 3-5. The properties not listed in the tables at other temperatures can be estimated by linear interpolation. Heat transfer analyses were carried out with three dimensional twenty-node DC3D20 elements. Thermal-mechanical analyses were carried out with three dimensional twenty-node C3D20 elements. A mesh convergence study had been performed, and showed that the mesh size was sufficient for the stress within the critical region to converge.

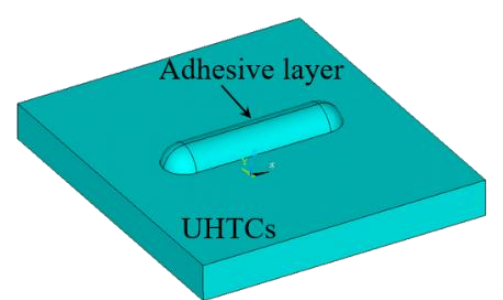

(a)

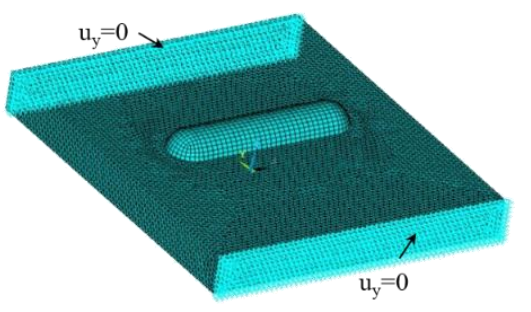

(b)

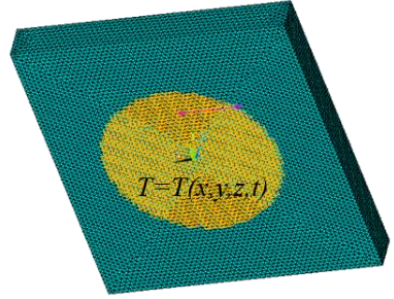

(c)

Figure 6. (a) Finite element model; (b) mechanical and (c) thermal boundary conditions of finite element analysis.

Table 2. Dimensions of the adhesive layer and UHTC specimen.

\begin{tabular}{ccccccc}
\hline \multirow{2}{*}{ Parameter } & \multicolumn{3}{c}{ Adhesive Layer } & \multicolumn{3}{c}{ UHTC Specimen } \\
\cline { 2 - 7 } & Length & Width & Height (Sagitta) & Length & Width & Thickness \\
\hline Value $(\mathrm{mm})$ & 20 & 6 & 2.5 & 45 & 40 & 5 \\
\hline
\end{tabular}

Table 3. Mechanical properties of the UHTC material [51,52].

\begin{tabular}{cccccc}
\hline \multirow{2}{*}{$\begin{array}{c}\text { Density } \\
\left.\mathbf{( k g} / \mathbf{m}^{\mathbf{3}}\right)\end{array}$} & $\begin{array}{c}\text { Poisson's } \\
\text { Ratio }\end{array}$ & \multicolumn{2}{c}{ Elastic Modulus (GPa) } & \multicolumn{2}{c}{ Compressive Strength (MPa) } \\
\cline { 3 - 6 } & $\mathbf{2 0}{ }^{\circ} \mathbf{C}$ & $\mathbf{1 4 0 0}^{\circ} \mathbf{C}$ & $\mathbf{2 0}^{\circ} \mathbf{C}$ & $\mathbf{8 0 0}^{\circ} \mathbf{C}$ \\
\hline 4960 & 0.165 & 463.0 & 158.7 & 1106.4 & 1009.2 \\
\hline
\end{tabular}

Table 4. Thermal properties of the UHTC material $[40,53]$.

\begin{tabular}{cccccccc}
\hline $\mathbf{T}\left({ }^{\circ} \mathbf{C}\right)$ & $\mathbf{2 0}$ & $\mathbf{3 0 3}$ & $\mathbf{5 9 4}$ & $\mathbf{8 9 1}$ & $\mathbf{1 1 9 6}$ & $\mathbf{1 4 9 9}$ & $\mathbf{1 8 0 6}$ \\
\hline Thermal conductivity $\left(\mathrm{W} / \mathrm{m} \cdot{ }^{\circ} \mathrm{C}\right)$ & 112.00 & 110.63 & 88.86 & 67.70 & 61.67 & 64.04 & 50.77 \\
Specific heat $\left(\mathrm{J} / \mathrm{kg} \cdot{ }^{\circ} \mathrm{C}\right)$ & 700.00 & 777.61 & 828.19 & 869.36 & 1013.46 & 1016.08 & 1083.27 \\
$\mathrm{CTE}\left(10^{-6}{ }^{\circ} \mathrm{C}^{-1}\right)$ & 3.31 & 5.45 & 6.67 & 7.20 & 7.62 & 8.03 & 8.43 \\
\hline
\end{tabular}


Table 5. Properties of the adhesive material [54].

\begin{tabular}{cccccc}
\hline $\begin{array}{c}\text { Density } \\
\left(\mathbf{k g} / \mathbf{m}^{\mathbf{3}}\right)\end{array}$ & $\begin{array}{c}\text { CTE } \\
\left(\mathbf{1 0}{ }^{-6}{ }^{\circ} \mathbf{C}^{-\mathbf{1}}\right)\end{array}$ & $\begin{array}{c}\text { Thermal Conductivity } \\
\left(\mathbf{W} / \mathbf{m}^{\circ}{ }^{\circ} \mathbf{C}\right)\end{array}$ & $\begin{array}{c}\text { Specific Heat } \\
\left(\mathbf{J} / \mathbf{k g} \cdot{ }^{\circ} \mathbf{C}\right)\end{array}$ & $\begin{array}{c}\text { Elastic Modulus } \\
(\mathrm{GPa})\end{array}$ & $\begin{array}{c}\text { Poisson's } \\
\text { Ratio }\end{array}$ \\
\hline 3700 & $8.1 \mathrm{E}-6$ & 85.18 & 1004.16 & 370 & 0.2 \\
\hline
\end{tabular}

The mechanical and thermal boundary conditions are illustrated in Figure $6 \mathrm{~b}, \mathrm{c}$. The displacements of two side faces of the specimen along the vertical direction were fixed to the constraints representing the horizontal vice. The temperature history curve measured during the experimental test (Figure 7) was applied to the bottom surface of the specimen as the temperature boundary condition. The total heating time was $2570 \mathrm{~s}$. Heating area was a $25 \mathrm{~mm}$ diameter circular area, which is the same as that of the laser heater spot. Other areas of the bottom and top surface were specified as the radiation boundary condition with a surface emissivity of 0.85 . Natural convection was not considered in this study. Both the UHTC and adhesive layer were assumed be isotropic materials and remained in the linear elastic range during analysis, and they were always perfectly bonded to each other. The experimental simulation was carried out based on the sequential coupled thermo-mechanical analysis with a Newton-Raphson method.

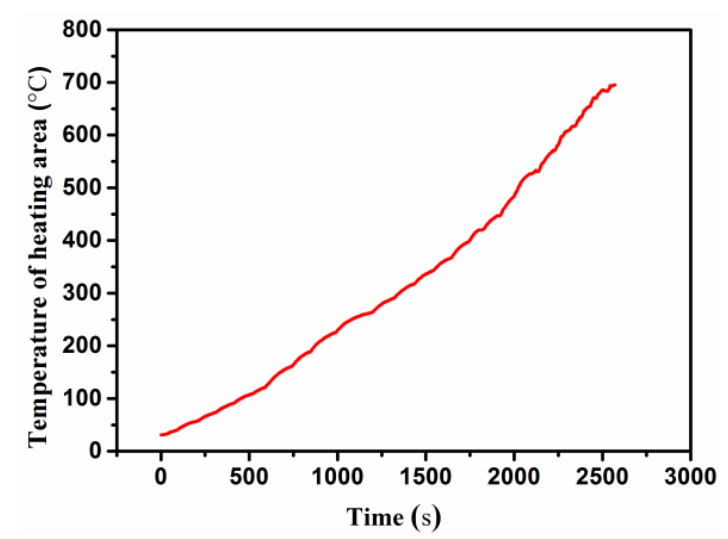

Figure 7. Temperature history curve of the experimental test.

\subsection{Results and Discussion}

The temperature distributions at the end of the thermal analysis are given in Figure 8 . It can be seen that the maximum temperature of the specimen at the centre reached the value of $695{ }^{\circ} \mathrm{C}$ while the minimum temperature was $681.2^{\circ} \mathrm{C}$ and localised at the corners of the specimen. The large thermal conductivity value of the UHTCs material made the maximum temperature difference lower than $14^{\circ} \mathrm{C}$.

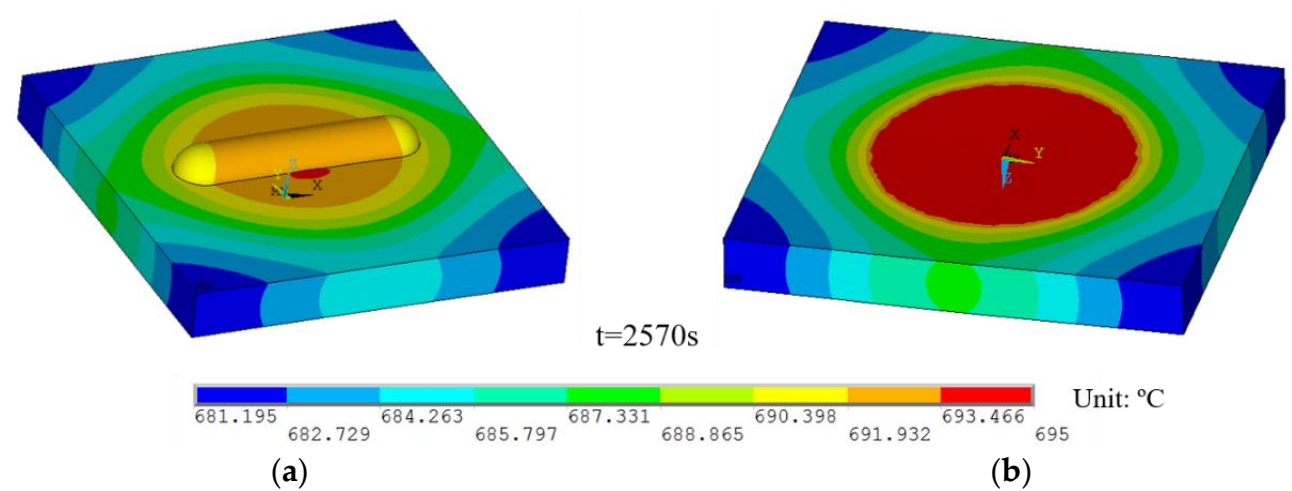

Figure 8. Temperature contour of (a) top view and (b) bottom view at $2570 \mathrm{~s}$. 
The temperature field distribution has been used as a thermal load to predict the internal stresses in the structure. The transient stress analysis results showed that the primary stress on the specimen was a compressive one (vertical to the CCG), and was caused by the constraints provided by the horizontal vice. By comparing the thermal stress contours at different times, it is possible to draw the same conclusion about the specimen's stress along the y-direction: stresses are always negative (i.e., compressive), and the minimum compressive stress in absolute value is located at the bonding region between the UHTC and the adhesive layer, while the maximum compressive stress (magnitude) is located in the area around the boundary of the bonding area. The compressive stress distributions along the y-direction without an adhesive layer at $1900 \mathrm{~s}$ and $2000 \mathrm{~s}$ are shown in Figure 9a,b. The compressive stress at the four borders reached $1053 \mathrm{MPa}$ at $1900 \mathrm{~s}$ (Figure 9a) and exceeded the UHTCs' compressive tensile strength at that specific temperature $\left(446{ }^{\circ} \mathrm{C}\right)$.

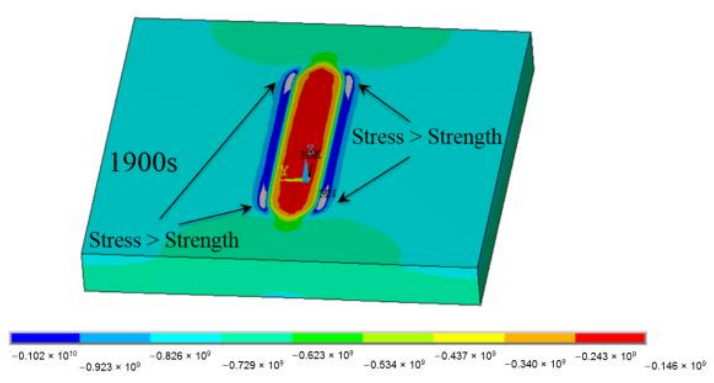

(a)

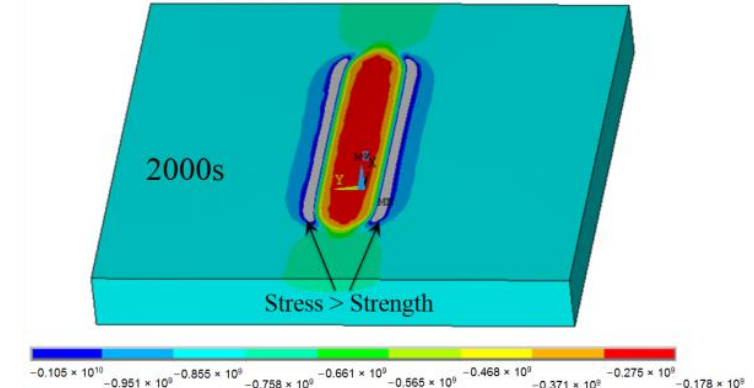

(b)

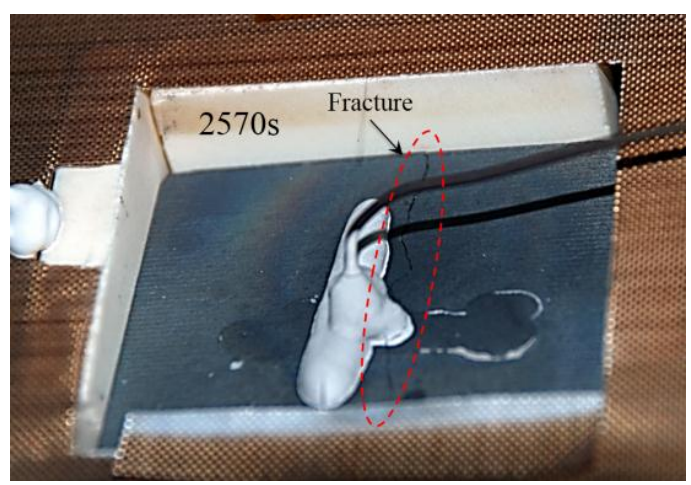

(c)

Figure 9. Comparison of failure positions between FEA and test at (a) $1900 \mathrm{~s}$; (b) $2000 \mathrm{~s}$; (c) $2570 \mathrm{~s}$.

According to the FE analysis, the temperature of the border after $2000 \mathrm{~s}$ was around $484{ }^{\circ} \mathrm{C}$, and the corresponding compressive strength was $1048 \mathrm{MPa}$. Two strip-shaped areas near the connection region exceeded their compressive strength (Figure 9b). If we compare the locations of the failure with the fracture point shown in Figure 9c, it is apparent that the fracture occurred in the location corresponding to the maximum compressive stress. The FEA results provide evidence to justify the observed experimental results. The micro-cracks present in the structure may have been generated as a result of the constrained thermal expansion after $2000 \mathrm{~s}$, followed by crack propagation until fracture occurred.

The strain on the specimen can also be obtained from the FEA analysis. We selected all the nodes along the line where the CCG was bonded at the UHTCs' adhesive surface, then calculated the average value of the nodal mechanical strains along the $x$-direction and obtained the strain versus time and temperature curves. These numerical values were then compared with the strain values measured by the CCG sensor (Figure 10a). By comparing the finite element simulation results with the experimental data we found that the results of the two methods are in good agreement. Table 6 provides the relative error of the two results, which decreased for increasing temperatures. The relative error was however 
larger in the low temperature regime (less than $100{ }^{\circ} \mathrm{C}$ ), due to the strain value being itself very small. Above $200{ }^{\circ} \mathrm{C}$ the relative error was less than $15 \%$, and the relative error between the two methods at the final temperature of $695^{\circ} \mathrm{C}$ was only $6.71 \%$.

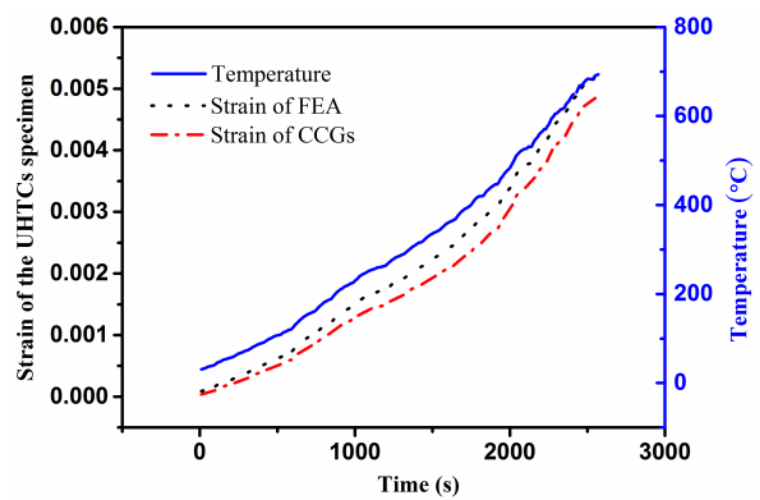

(a)

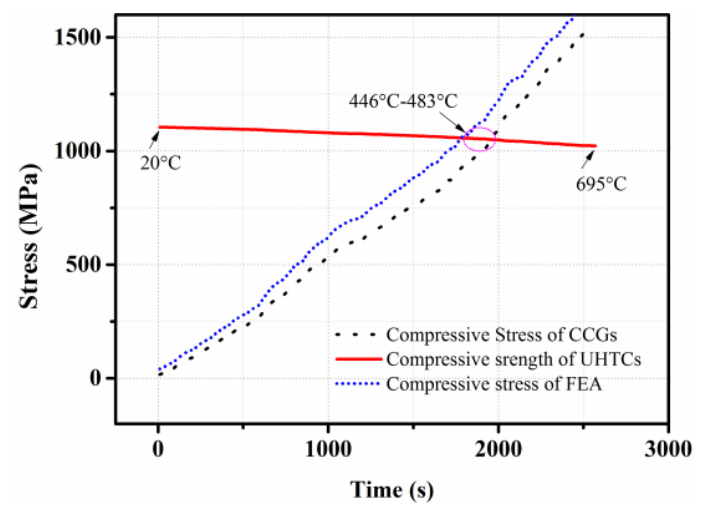

(b)

Figure 10. The curves of (a) strain and (b) stress over time.

Table 6. Relative errors of mechanical strain between FEA and experimental results.

\begin{tabular}{cccccccc}
\hline Temperature $\left({ }^{\circ} \mathrm{C}\right)$ & $\mathbf{1 0 0}$ & $\mathbf{2 0 0}$ & $\mathbf{3 0 0}$ & $\mathbf{4 0 0}$ & $\mathbf{5 0 0}$ & $\mathbf{6 0 0}$ & $\mathbf{6 9 5}$ \\
\hline Relative Errors & $18.96 \%$ & $14.92 \%$ & $13.79 \%$ & $13.19 \%$ & $9.91 \%$ & $8.10 \%$ & $6.71 \%$ \\
\hline
\end{tabular}

Within the elastic range we can use the strain to calculate the corresponding stresses, according to Hooke's law. As shown in Figure 10b, the structural compressive stress curves were calculated over time by using the strain of the FEA and the CCG sensor. At the same time, the compressive strength of the UHTC at the corresponding temperature was also obtained (see Figure 10b). Both compressive stresses were greater than the material compressive strength in the $1900 \mathrm{~s}-2000 \mathrm{~s}$ range, and the temperature range of the corresponding times were roughly $446{ }^{\circ} \mathrm{C}-483{ }^{\circ} \mathrm{C}$, respectively. This was in agreement with the experimental results.

The discrepancies between simulations and experimental results were mainly derived from the representation of the boundary conditions and assumptions like the use of adiabatic boundary conditions. In the actual experiment, it was difficult to completely insulate the specimen from the surrounding environment and to keep the applied displacement constraints constants. Nonetheless, the results show that the FE model is capable to represent the physics and provide some robust predictions about the thermo-mechanical coupling occurring inside the structure.

\section{Conclusions}

In this work, the application of a CCG fibre optic sensor on a hot structure was evaluated and a simple method to perform a combined thermal and mechanical load test has been presented. A high temperature test was performed on a UHTC specimen that was subjected to thermo-mechanical loads. The response characteristics of the bonded CCG were highlighted by a signal decoupling technique on the basis of a temperature compensation method. The results showed that the relative error between the test results and the theoretical strain value was less than $2.15 \%$. The finite element method was used to simulate the experimental process, and the temperature field, stress field and strain field were calculated and analysed. The finite element analysis showed that the compressive stress of the connecting region exceeded the strength value of the material in the thermo-mechanical coupling environment, which explains the failure of the hot supporting structure. Numerical simulations can accurately predict the location and time of the failure of thermal structures, as well as the corresponding stress failure values. The numerical analysis can also reasonably explain the failure mechanism 
observed during the test. Furthermore, the numeric simulation results showed that the relative error of the strain decreased alongside an increase in temperature. The relative error was lower than $15 \%$ when the temperature was higher than $200{ }^{\circ} \mathrm{C}$ and only $6.71 \%$ at $695{ }^{\circ} \mathrm{C}$.

Acknowledgments: This research was supported by the Project of National Natural Science Foundation of China (11272107, 11472092 and 11502058) and the National Basic Research Program of China (2015CB655200). The authors thank the Institute of Photonics Technology (Jinan University, Guangzhou, China) for providing CCG sensors.

Author Contributions: W.X. and S.M. conceived and designed the experiments; L.W. and T.P. performed the experiments; H.J. and F.S. analyzed the experimental data; C.D. and C.X. contributed to the specimen manufacturing and FE analysis; W.X. and F.S. wrote the paper.

Conflicts of Interest: The authors declare no conflict of interest.

\section{References}

1. Mihailov, S.J. Fiber bragg grating sensors for harsh environments. Sensors 2012, 12, 1898-1918. [CrossRef] [PubMed]

2. Panopoulou, A.; Roulias, D.; Loutas, T.; Kostopoulos, V. Health monitoring of aerospace structures using fibre bragg gratings combined with advanced signal processing and pattern recognition techniques. Strain 2012, 48, 267-277. [CrossRef]

3. Su, D.; Qiao, X.; Yang, H.; Rong, Q.; Bai, Z.; Wang, Y.; Feng, Z. Temperature-independent fiber inclinometer based on orthogonally polarized modes coupling using a polarization-maintaining fiber bragg grating. Sensors 2014, 14, 20930-20939. [CrossRef] [PubMed]

4. Wang, J.-N.; Tang, J.-L. Feasibility of fiber bragg grating and long-period fiber grating sensors under different environmental conditions. Sensors 2010, 10, 10105-10127. [CrossRef] [PubMed]

5. Culshaw, B. Measuring strain using optical fibres. Strain 2000, 36, 105-113. [CrossRef]

6. Bennion, I.; Zhang, L.; Everall, L. In-fibre grating techniques for strain sensing. Strain 2000, 36, 115-121. [CrossRef]

7. Canning, J.; Stevenson, M.; Bandyopadhyay, S.; Cook, K. Extreme silica optical fibre gratings. Sensors 2008, 8, 6448-6452. [CrossRef]

8. Bueno, A.; Kinet, D.; Mégret, P.; Caucheteur, C. Fast thermal regeneration of fiber bragg gratings. Opt. Lett. 2013, 38, 4178-4181. [CrossRef] [PubMed]

9. Fokine, M. Thermal Stability of Chemical Composition Gratings in Fluorine-Germanium-Doped Silica Fibers. Opt. Lett. 2002, 27, 1016-1018. [CrossRef] [PubMed]

10. Fokine, M. Photosensitivity, Chemical Composition Gratings and Optical Fiber Based Components. Ph.D. Thesis, Royal Institute of Technology, Stockholm, Sweden, December 2002.

11. Fokine, M. Formation of thermally stable chemical composition gratings in optical fibers. J. Opt. Soc. Am. B 2002, 19, 1759-1765. [CrossRef]

12. Pal, S.; Mandal, J.; Sun, T.; Grattan, K.; Fokine, M.; Carlsson, F.; Fonjallaz, P.Y.; Wade, S.; Collins, S. Characteristics of potential fibre bragg grating sensor-based devices at elevated temperatures. Meas. Sci. Technol. 2003, 14, 1131. [CrossRef]

13. Fokine, M. Thermal stability of oxygen-modulated chemical-composition gratings in standard telecommunication fiber. Opt. Lett. 2004, 29, 1185-1187. [CrossRef] [PubMed]

14. Holmberg, P.; Laurell, F.; Fokine, M. Influence of pre-annealing on the thermal regeneration of fiber bragg gratings in standard optical fibers. Opt. Express 2015, 23, 27520-27535. [CrossRef] [PubMed]

15. Zhang, B. Optical High Temperature Sensor Based on Fiber Bragg Grating. Ph.D. Thesis, Concordia University, Montreal, QC, Canada, October 2007.

16. Zhang, B.; Kahrizi, M. High-temperature resistance fiber bragg grating temperature sensor fabrication. IEEE Sens. J. 2007, 7, 586-591. [CrossRef]

17. Bandyopadhyay, S.; Canning, J.; Stevenson, M.; Cook, K. Ultrahigh-temperature regenerated gratings in boron-codoped germanosilicate optical fiber using $193 \mathrm{~nm}$. Opt. Lett. 2008, 33, 1917-1919. [CrossRef] [PubMed] 
18. Canning, J.; Stevenson, M.; Fenton, J.; Aslund, M.; Bandyopadhyay, S. Strong regenerated gratings. In Proceedings of the 20th International Conference on Optical Fibre Sensors, Edinburgh, UK, 5-9 October 2009.

19. Canning, J.; Cook, K.; Aslund, M.; Stevenson, M.; Biswas, P.; Bandyopadhyay, S. Regenerated Fibre Bragg Gratings; InTech: Rijeka, Croatia, 2010.

20. Barrera, D.; Finazzi, V.; Coviello, G.; Bueno, A.; Sales, S.; Pruneri, V. Chemical composition gratings in germanium doped and boron-germanium co-doped fibers. In Proceedings of the Optical Sensing and Detection, Brussels, Belgium, 12-15 April 2010.

21. David, B.; Vittoria, F.; Joel, V.; Antonio, B.; Salvador, S.; Valerio, P. On the Use of Optical Fiber Sensors (CCGs and PCFI) for Harsh Environments. Waves 2010, 126-133. Available online: http:/ / citeseerx.ist.psu.edu / viewdoc/download?doi=10.1.1.722.5293\&rep=rep1\&type=pdf (accessed on 13 September 2016).

22. Barrera, D. Fiber-optic sensors for high-temperature applications. SPIE Newsroom 2010, 6. [CrossRef]

23. Li, G.; Guan, B.O. Research on reflectivity of chemical composition grating sensors at high temperatures. In Proceedings of the Passive Components and Fiber-Based Devices VII, Shanghai, China, 8-12 December 2010.

24. Li, G.; Guan, B.O. Improvement on reflectivity of chemical composition gratings at high temperatures. Microw. Opt. Technol. Lett. 2011, 53, 963-966. [CrossRef]

25. Li, G.; Liu, M.; Li, Y.; Guan, B.O. Fabrication and sensing characteristics of the chemical composition grating sensor at high temperatures. Microw. Opt. Technol. Lett. 2012, 54, 71-75. [CrossRef]

26. Grobnic, D.; Smelser, C.W.; Mihailov, S.J.; Walker, R.B. Long-term thermal stability tests at $1000{ }^{\circ} \mathrm{C}$ of silica fibre bragg gratings made with ultrafast laser radiation. Meas. Sci. Technol. 2006, 17, 1009. [CrossRef]

27. Coviello, G.; Finazzi, V.; Villatoro, J.; Pruneri, V. Thermally stabilized pcf-based sensor for temperature measurements up to $1000{ }^{\circ} \mathrm{C}$. Opt. Express 2009, 17, 21551-21559. [CrossRef] [PubMed]

28. Cheong, Y.; Chong, W.; Chong, S.; Lim, K.; Ahmad, H. Regenerated type-iia fibre bragg grating from a Ge-B codoped fibre via thermal activation. Opt. Laser Technol. 2014, 62, 69-72. [CrossRef]

29. Laffont, G.; Cotillard, R.; Ferdinand, P. Multiplexed regenerated fiber bragg gratings for high-temperature measurement. Meas. Sci. Technol. 2013, 24, 094010. [CrossRef]

30. Lindner, E.; Canning, J.; Chojetzki, C.; Brückner, S.; Becker, M.; Rothhardt, M.; Bartelt, H. Thermal regenerated type iia fiber bragg gratings for ultra-high temperature operation. Opt. Commun. 2011, 284, 183-185. [CrossRef]

31. Méndez, A.; Wnuk, V.P.; Fokine, M.; Claesson, Å.; Nilsson, L.-E.; Ferguson, S.; Graver, T. Packaging process of fiber bragg grating strain sensors for use in high-temperature applications. In Proceedings of the Fiber Optic Sensor Technology and Applications IV, Boston, MA, USA, 24-26 October 2005.

32. Wnuk, V.P.; Méndez, A.; Ferguson, S.; Graver, T. Process for mounting and packaging of fiber bragg grating strain sensors for use in harsh environment applications. In Proceedings of the Smart Structures and Materials 2005: Smart Sensor Technology and Measurement System, San Diego, CA, USA, 5-6 March 2005.

33. Selfridge, R.H.; Schultz, S.M.; Lowder, T.L.; Wnuk, V.P.; Méndez, A.; Ferguson, S.; Graver, T. Packaging of surface relief fiber bragg gratings for use as strain sensors at high temperature. In Proceedings of the Smart Structures and Materials 2006: Smart Sensor Monitoring Systems and Applications, San Diego, CA, USA, 27 February-1 March 2006.

34. Reddy, P.S.; Sai Prasad, R.L.; Srimannarayana, K.; Shankar, M.S.; Gupta, D.S. A novel method for high temperature measurements using fiber bragg grating sensor. Opt. Appl. 2010, 40, 685-692.

35. Mamidi, V.R.; Kamineni, S.; Ravinuthala, L.S.P.; Thumu, V.; Pachava, V.R. Characterization of encapsulating materials for fiber bragg grating-based temperature sensors. Fiber Integr. Opt. 2014, 33, 325-335. [CrossRef]

36. Reddy, P.S.; Prasad, R.L.N.S.; Gupta, D.S.; Shankar, M.S.; Narayana, K.S.; Kishore, P. Encapsulated fiber bragg grating sensor for high temperature measurements. Opt. Eng. 2011, 50, 114401-114406. [CrossRef]

37. Barrera, D.; Finazzi, V.; Villatoro, J.; Sales, S.; Pruneri, V. Performance of a high-temperature sensor based on regenerated fiber bragg gratings. In Proceedings of the 21st International Conference on Optical Fibre Sensors (OFS21), Ottawa, ON, Canada, 15-19 May 2011; pp. 775381-775384.

38. Barrera, D.; Finazzi, V.; Villatoro, J.; Sales, S.; Pruneri, V. Packaged optical sensors based on regenerated fiber bragg gratings for high temperature applications. IEEE Sens. J. 2012, 12, 107-112. [CrossRef]

39. Azhari, A.; Liang, R.; Toyserkani, E. A novel fibre bragg grating sensor packaging design for ultra-high temperature sensing in harsh environments. Meas. Sci. Technol. 2014, 25, 075104. [CrossRef] 
40. Xie, W.; Meng, S.; Jin, H.; Du, C.; Wang, L.; Peng, T.; Scarpa, F.; Huo, S. Measurement of the high-temperature strain of uhtc materials using chemical composition gratings. Meas. Sci. Technol. 2016, 27, 055101. [CrossRef]

41. Glass, D.E. Ceramic matrix composite (CMC) thermal protection systems (TPS) and hot structures for hypersonic vehicles. In Proceedings of the 15th AIAA Space Planes and Hypersonic Systems and Technologies Conference, Dayton, OH, USA, 28 April-1 May 2008; pp. 1-36.

42. Latini, V.; Striano, V.; Coppola, G.; Rendina, I. Fiber optic sensors system for high-temperature monitoring of aerospace structures. In Proceedings of the Photonic Materials, Devices, and Applications II, Maspalomas, Spain, 2-4 May 2007.

43. Manor, D.; Lau, K.Y.; Johnson, D.B. Aerothermodynamic environments and thermal protection for a wave-rider second stage. J. Spacecr. Rockets 2005, 42, 208-212. [CrossRef]

44. Zhang, X.-H.; Hu, P.; Han, J.-C. Structure evolution of $\mathrm{ZrB}_{2}-\mathrm{SiC}$ during the oxidation in air. J. Mater. Res. 2008, 23, 1961-1972. [CrossRef]

45. Ge, Y.; Elshafie, M.Z.; Dirar, S.; Middleton, C.R. The response of embedded strain sensors in concrete beams subjected to thermal loading. Constr. Build. Mater. 2014, 70, 279-290. [CrossRef]

46. Li, G.-Y.; Guan, B.O. The strain response of chemical composition gratings at high temperatures. Meas. Sci. Technol. 2009, 20, 025204. [CrossRef]

47. Maier, R.R.; MacPherson, W.N.; Barton, J.S.; Jones, J.D.; McCulloch, S.; Burnell, G. Temperature dependence of the stress response of fibre bragg gratings. Meas. Sci. Technol. 2004, 15, 1601. [CrossRef]

48. Meng, S.; Du, C.; Xie, W.; Huo, S.; Jiao, L.; Jin, H.; Song, L. Application of high-temperature optical fiber sensor in temperature and strain testing of hot structure. J. Sol. Rocket Technol. 2013, 36, 701-705.

49. Du, C.; Xie, W.; Meng, S.; Yin, Y.; Jiao, L.; Song, L. The connection technology based on high temperature silica fiber optic sensor. In Proceedings of the Sensors and Smart Structures Technologies for Civil, Mechanical, and Aerospace Systems 2012, San Diego, CA, USA, 11-15 March 2012.

50. Du, C.; Xie, W.; Huo, S.; Meng, S.; Xu, K.; Jiao, L. The response of high-temperature optical fiber sensor applied to different materials. In Proceedings of the Fourth International Conference on Smart Materials and Nanotechnology in Engineering, Gold Coast, Australia, 10-12 July 2013.

51. Wang, L.; Fang, G.; Liang, J.; Wang, C. Formation mechanism and high temperature mechanical property characterization of $\mathrm{SiC}$ depletion layer in $\mathrm{ZrB}_{2} / \mathrm{SiC}$ ceramics. Mater. Charact. 2014, 95, 245-251. [CrossRef]

52. Wang, L.-L.; Liang, J.; Fang, G.-D.; Wan, X.-Y.; Xie, J.-B. Effects of strain rate and temperature on compressive strength and fragment size of $\mathrm{ZrB}_{2}-\mathrm{SiC}-$ Graphite composites. Ceram. Int. 2014, 40, 5255-5261. [CrossRef]

53. Wang, Z.; Hong, C.; Zhang, X.; Sun, X.; Han, J. Microstructure and thermal shock behavior of $\mathrm{ZrB}_{2}$-SiC-Graphite composite. Mater. Chem. Phys. 2009, 113, 338-341. [CrossRef]

54. $3000^{\circ} \mathrm{F}$ Resbond ${ }^{\mathrm{TM}}$ 989FS High Purity Alumina Adhesive Rapid Curing Formulation. Available online: http:/ / www.cotronics.com/WEB\%20SHEETS/989FS\%20NP.pdf (accessed on 13 September 2016).

(C) 2016 by the authors; licensee MDPI, Basel, Switzerland. This article is an open access article distributed under the terms and conditions of the Creative Commons Attribution (CC-BY) license (http://creativecommons.org/licenses/by/4.0/). 